\title{
O CÂNTICO DE SALOMÃO E O EROTISMO: OBSERVAÇÕES SOBRE IMAGEM E SOBREVIVÊNCIA
}

Fabio Andrade*

https://orcid.org/0000-0002-3720-0343

Como citar este artigo: ANDRADE, F. O Cântico de Salomão e o erotismo: observações sobre imagem e sobrevivência. Todas as Letras - Revista de Lingua e Literatura, São Paulo, v. 23, n. 3, p. 1-11, set./dez. 2021. DOI 10.5935/1980-6914/eLETDO2114897

Submissão: outubro de 2021. Aceite: novembro de 2021.

Resumo: A incidência da união entre o sagrado e o profano, entre desejo e sacralidade, é um traço marcante da literatura tocada pelo erotismo. O objetivo deste artigo é tecer algumas considerações sobre a presença do Cântico de Salomão e de sua linguagem na literatura moderna. O conceito de sobrevivência do teórico alemão Aby Warburg permite perceber a recorrência de um tipo de linguagem metafórica que se realiza por meio de uma fórmula de pathos ancestral, quando a natureza integra com o humano o corpo amoroso e místico.

Palavras-chave: Cântico de Salomão. Árvore da vida. Sobrevivência. Aby Warburg. Avalovara.

\section{INTRODUÇÃO}

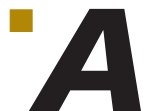

primeira coisa que devo dizer é que este artigo não resulta do trabalho de um especialista em literatura bíblica e judaica antiga. Não é o exercício de um perito nesse campo, mas de um pesquisador que foi recolhendo aqui e ali notas sobre o importante papel que o Cântico de Salomão 
teve no erotismo literário do Ocidente. Essa é uma ressalva deveras importante a ser feita, para que se entenda o objetivo do breve e pontual conjunto de reflexões que este texto almeja.

Poderia resumi-lo da seguinte maneira: as imagens e metáforas do Cântico, independentemente de sua provável origem remota - anterior ao texto bíblico assinalam uma série de modos de representação da experiência erótica e amorosa que deixaram marcas profundas na literatura ocidental. Obviamente, exemplificar ou apresentar minimamente essa fortuna seria impossivel no esquadro exíguo do meu texto. Já seria impossivel num trabalho de mestrado e mesmo de doutorado, dada a vastidão e complexidade do assunto. Assim, decidi assumir o risco de maneira ainda mais atrevida: a presença do texto salomônico será discutida à luz do conceito de Nachleben (sobrevivência) a partir de dois eixos básicos: 1 . o caráter místico da experiência erótica; 2 . as metáforas de procedência natural, e principalmente vegetal, que exprimem essa experiência.

Socorre-me para atravessar milênios de tradição literária o conceito de sobrevivência de Aby Warburg, grande estudioso da arte renascentista e pensador inclassificável. O seu conceito de sobrevivência me permitirá, com todos os riscos que esse tipo de empreitada sugere, uma mobilidade maior e mais despojada, permitindo-me, inclusive, aproximar o Cântico, o romance Avalovara (1973) e um motivo recorrente da iconografia religiosa (não só de origem judaico-cristã).

\section{O erotismo e a natureza no Cântico de Salomão}

A primeira afirmação sobre o caráter erótico do texto salomônico que desejo sustentar é a de que, independentemente de o texto significar essa ou aquela analogia segundo a tradição midráshica ${ }^{1}$ e mesmo cristã, isso não subtrai dele o seu erotismo, porque o erotismo é uma forma de linguagem. Em outras palavras: as copiosas e sensoriais metáforas não dizem apenas de alegorias com as quais se socorre a tradição exegética; são a própria forma de ser do erotismo, um excesso que exulta por meio da linguagem. Esse caráter erótico do texto canônico foi motivo de muita discussão e controvérsia.

Como toda uma tradição crítica já ressaltou, o Cântico é uma trama complexa de elementos literários e culturais diversos, advindos dos mundos assírio-babilônico, egípcio, grego e hebraico. Sua linguagem direta e clara sobre os prazeres do corpo do amado e da amada exigiu, ao longo dos séculos, uma expansão engenhosa de seus possiveis significados que corresponde tanto ao caráter poético de sua linguagem quanto às desconcertantes imagens que o compõem. Foi essa linguagem sutil, que ora revela, ora oculta, num metaforismo obliquo, que se transformou também em modelo para definir o erotismo como aceitável, contrapondo-o ao pornográfico. Esse casamento entre religiosidade e prazer corporal encontra na metáfora naturalista um princípio recorrente na literatura. Eu arriscaria apresentar duas hipóteses para compreender esse substrato imemorial, para além do fato de que a natureza, evidentemente, é o princípio de alteridade fundamental para o homem ancestral em sua descoberta imaginária do mundo e de si mesmo - espelho que o deforma e no qual ele se observa em comunhão e dissenso, ao mesmo tempo.

1 A Midrash é a linha de exegese profunda das Escrituras na tradição judaica. Seu objetivo é revelar o sentido oculto do texto bíblico, elucidando os significados que não se revelam na superfície do texto. 
A primeira hipótese é consubstancial à própria natureza da linguagem metafórica, como bem a descreve Octavio Paz. É filha do tabu, dos interditos e, nesse caso, a sexualidade configura-se como um dos interditos fundamentais - no sentido mesmo em que fundamenta a cultura. Para Octavio Paz (1977, p. 15), "A proibição do incesto nos faz defrontar, noutro plano, com o próprio enigma da linguagem [...]". Metáfora e tabu, deslocamento e interdito seriam consubstanciais à linguagem poética. A segunda hipótese é mais de ordem filosófica e antropológica do que linguística: como a natureza se caracteriza por um fluxo que ultrapassa o problema da identidade, os limites da subjetividade humana se veem ameaçados por esse fluir ininterrupto, por uma continuidade, diria Georges Bataille (2017), que põe em xeque a unidade a que aspiramos ao firmarmos nossas forças enunciativas nesse quinhão chamado "eu". Diferentemente da natureza, regida por uma lógica da continuidade, o homem se vê marcado pela descontinuidade, ameaçado pela continuidade que a experiência erótica o faz vivenciar. Como se o prazer sexual the pudesse restituir temporariamente a continuidade própria do estado animal e natural.

Assim são as metáforas que permeiam o Cântico. As propriedades naturais, os atributos dos elementos, o amplo espectro da experiência sensorial que deriva da natureza compõem o corpo erótico dos amantes. No fragmento que segue, para além do elogio do artifício humano em cotejo com a natureza artífice, predominam as fusões desse corpo erótico com a natureza:

(2) Os teus pés... como são belos nas sandálias, ó filha de nobres; as curvas dos teus quadris, que parecem colares, obras de um artista. (3) Teu umbigo... essa taça redonda onde o vinho nunca falta; teu ventre, monte de trigo rodeado de açucenas; (4) teus seios, dois filhotes, filhos gêmeos de gazela; (5) teu pescoço, uma torre de marfim; teus olhos, as piscinas de Hesebon junto às portas de Bat-Rabim. Teu nariz, como a torre do Libano voltada para Damasco; (6) tua cabeça que se alteia como o Carmelo, e teus cabelos cor de púrpura, enlaçando um rei nas tranças. (7) Como és bela, quão formosa, que amor delicioso! (8) Tens o talhe da palmeira, e teus seios são os cachos. (9) Pensei: "Vou subir à palmeira para colher dos seus frutos!" Sim, teus seios são cachos de uva, e o sopro das tuas narinas perfuma como o aroma das maçãs. (10) Tua boca é um vinho delicioso que se derrama na minha molhando-me lábios e dentes (Cântico dos Cânticos 10:2-10).

Por outro lado, essa aliança com a continuidade da natureza, essa conjunção com o eterno fluir de uma inconsciência "original", tem repercussões espirituais que não serão estranhas à tradição mística em geral, seja ela ocidental ou oriental.

\section{O CARÁTER SAGRADO DA EXPERIÊNCIA ERÓTICA}

São vários os momentos em que, no pensamento de Octavio Paz (2001), a experiência erótica é explorada em sua sacralidade. A matéria-prima dessas reflexões são as tradições de poesia mística, ocidental e oriental. Em A dupla chama, por exemplo, o ensaísta e poeta mexicano lembra-nos que "Cada uma das grandes religiões históricas engendrou, externa ou internamente, seitas, movimentos, ritos e liturgias nas quais a carne e o sexo são caminhos em direção à divindade" (PAZ, 2001, p. 20). Desde épocas remotíssimas, a experiência poética parece constituir um espaço privilegiado de manifestação dessa conexão 
entre sexo e fé. Aliás, a nossa própria época também não escapa à incidência dessa camada profunda e ancestral. Octavio Paz (2001, p. 22) contrapõe o judaísmo ao cristianismo, pois, segundo ele, no primeiro "o desprezo ao corpo não aparece", havendo espaço inclusive para a exaltação dos "poderes genéticos" (lembra ele do primeiro mandamento bíblico: "Crescei e multiplicai-vos"). No cristianismo, teria se espalhado um neoplatonismo derivado da filosofia dos grandes padres da igreja. De todo modo, a ênfase sobre a clara relação entre esses dois polos - o transcendente e o material - sobressai, segundo Paz, justamente no judaísmo que, tendo como base o Antigo Testamento, é "pródigo em histórias eróticas". O Cântico de Salomão entra nessa conta: "Como no caso do Cântico dos Cânticos, o sentido religioso do poema é indistinguivel de seu sentido erótico profano: são dois aspectos da mesma realidade" (PAZ, 2001, p. 23).

Georges Bataille insistiu no aspecto sagrado da relação sexual por outro caminho. Associando-o ao sacrificio, à natureza deliberadamente transgressora que o ato sacrificial assume para ele. O sacrificio subtrai da vítima a sua descontinuidade. Para Bataille (2017, p. 114), na imolação a vítima é reconduzida à "continuidade do ser, à ausência de particularidade". Nas suas palavras: "Essa ação violenta, que priva a vítima de seu caráter limitado e lhe dá o ilimitado, o infinito que pertence à esfera sagrada, é desejada em sua consequência profunda" (BATAILLE, 2017, p. 114). De todo modo, confirma-se a dissolução do "eu" como unidade estável, atravessada agora pela continuidade; e afirma, mesmo que de modo muito peculiar, pois diretamente relacionada à noção de sacrifício no pensamento de Bataille (2017, p. 116), a profunda conexão que subsiste entre o sagrado e a experiência erótica, pois:

O que o ato de amor e o sacrifício revelam é a carne. O sacrifício substitui a vida ordenada do animal pela convulsão cega dos órgãos. O mesmo se dá com a convulsão erótica: ela libera órgãos pletóricos cujos jogos cegos prosseguem além da vontade refletida dos amantes.

\section{O CONCEITO DE SOBREVIVÊNCIA}

O conceito de Nachleben, que poderia ser traduzido por sobrevivência ou vida póstuma, tem cada vez mais contribuído para um debate amplo nas ciências humanas nos últimos anos. A circulação do conceito, por sua vez, repõe a força com que o estudioso que o elaborou - Aby Warburg ${ }^{2}$ - marcou parte do pensamento sobre a arte e o papel da imagem na cultura ocidental ao longo do século XX. Sem dúvida, outro fator que muito contribuiu para esse renovado interesse no pensamento de Warburg foi sua influência decisiva sobre vários teóricos, historiadores e pensadores - entre eles, figuras da estatura de Giorgio Agamben, Carlo Ginzburg e Georges Didi-Huberman. Há um Warburg diferente - por vezes essas diferenças se avultam - em cada um desses pensadores. Coube a Didi-Huberman fazer do conceito de sobrevivência, assim como o de fórmulas de pathos (Pathosformeln), as principais chaves de leitura do universo warburguiano.

Elegendo muito cedo o Renascimento como um dos principais focos do seu olhar, Warburg procurou exprimir com o conceito de sobrevivência a atualização

2 Aby Warburg (1866-1929) foi um dos mais influentes e importantes historiadores da arte. Propôs releituras decisivas de certos períodos e aspectos da arte ocidental. Passou a se enxergar muito mais como um historiador das imagens do que da arte propriamente dita. Além disso, lançou as bases para uma abordagem mais antropológica da história da arte. 
de imagens recorrentes na cultura literária e artística, imagens obsedantes, que pareciam assombrar o imaginário cultural desde tempos remotos. Considero Warburg uma espécie de precursor dos estudos do imaginário. Até porque as imagens tinham para ele um valor simbólico fundamental, e daí deriva a iconologia enquanto campo de estudo da textura simbólica da arte, desdobrada por teóricos como Erwin Panofsky e E. H. Gombrich.

Warburg propôs uma releitura radical do Renascimento, destoando da visão que perdura até hoje. Para ele, o artista renascentista não retornava à Antiguidade para encontrar modelos de serenidade e harmonia na lógica da imitatio. $\mathrm{Na}$ verdade, o modelo mimético tradicional pressupõe uma consciência excessiva na busca de formas de excelência. Para Warburg, mais do que escolher o que imitar da Antiguidade, o artista era obsedado, assombrado por imagens que atravessavam o tempo dispersas, difusas, ocultas. Eram como cicatrizes mnêmicas no corpo da cultura e por onde toda uma memória profunda poderia ser reativada para exprimir um conteúdo simbólico transtemporal ${ }^{3}$. Desse ponto de vista, o Cântico pode representar a sobrevivência de uma linguagem antiquíssima, imemorial naquilo que de sagrado existe na experiência sexual. E assim, a força com que o texto se difundiu deriva também dessa trama de imagens e símbolos reavivados pela literatura e pela arte em geral, sensíveis à força nem sempre evidente dessas imagens.

Aproximo-me, assim, do centro da minha questão por meio dessa trama transtextual, que é por sua vez também transtemporal, ousando apontar exemplos da sobrevivência de uma linguagem primordial. Antes, porém, vale ainda seguir um pouco mais de perto o trabalho de Warburg para responder a uma questão que pode pairar sobre essas reflexões como uma sombra incômoda: ao dedicar-se à imagem, que tipo de repercussão o conceito warburguiano pode ter para o estudo do texto literário? Começaria respondendo a essa questão assinalando o interesse de Warburg pelo texto literário e pelo trânsito constante de imagens entre tradição figurativa e tradição literária. Sua tese de doutoramento apresentada na Universidade de Estrasburgo, um estudo do Nascimento de Vênus e A primavera, de Sandro Botticelli, aborda a apropriação que Botticelli faz de dois textos literários específicos, com o intuito de construir a cena da geração de sua Vênus: "O hino homérico a Afrodite", publicado numa tradução italiana de 1488; e o poema "Giostra", de Angelo Poliziano. Essa tendência em associar linguagens artísticas diferentes a partir da noção de imagem como um elemento de coligação entre elas só é possivel porque essa imagem, menos devedora da materialidade pictórica, enraíza-se, na verdade, no campo do imaginário cultural e constitui uma imagem simbólica. E as imagens simbólicas têm grande maleabilidade. Submetidas ao dinamo criador de momentos históricos diferentes, elas se deformam, decompõem-se, dividem-se, sofrem os mais variados tipos de deslocamento, embora algo ainda permita reconhecer alguns de seus elementos fundamentais: o pathos a que ela se associa e que se sustenta visual ou verbalmente em alguns elementos expressivos. Em resumo, a imagem de Afrodite e sua coreografia corpórea, parecendo ganhar movimento e beleza inusitada através da leitura de Warburg, vai realizando suas aparições, confirmando

\footnotetext{
Agamben (2012) chama a atenção para a influência que teóricos como Theodor von Vischer e Richard Semon tiveram sobre as ideias de Aby Warburg, principalmente a noção de engrama - uma marca indelével que certas experiências físicas gravam no tecido cerebral, de modo a serem reativadas de acordo com determinadas circunstâncias.
} 
a sua intensa vida póstuma... no poema de Homero, no poema do italiano Poliziano, na pintura do florentino Botticelli.

Georges Didi-Huberman (2013, p. 55) define com precisão o conceito de sobrevivência de Warburg:

A forma sobrevivente, no sentido de Warburg, não sobrevive triunfalmente à morte de suas concorrentes. Ao contrário, ela sobrevive, em termos sintomais $e$ fantasmais, à sua própria morte: desaparece num ponto da história, reaparece muito mais tarde, num momento em que talvez não fosse esperada, tendo sobrevivido, por conseguinte, no limbo ainda mal definido de uma memória coletiva.

Cabe então chamar a atenção sobre um aspecto importantíssimo, sugerido por Didi-Huberman. O do desaparecimento temporário da imagem, seu ocultamento transitório. O Cântico, entretanto, nunca deixou de ostentar um lugar de destaque no imaginário cultural e literário do Ocidente. Nesse sentido, e acompanhando bem de perto o método warburguiano, quero considerar o texto de Salomão em sua relação com uma imagem arcaica específica, com a qual ele se relaciona de maneira oblíqua. É a experiência mística amorosa das personagens do romance Avalovara (1973), do escritor Osman Lins, que possibilita iluminar a relação entre o texto salomônico e o motivo icônico que sobrevive deslocado no texto bíblico e na obra literária do escritor pernambucano, o que indica um caminho inverso: em vez de partir da imagem arcaica procurando suas repercussões, numa exigência convencional dos nexos causais (e aqui pesaria a necessidade de detectar como se deu historicamente esse trânsito), farei uma espécie de leitura arqueológica ao seguir rastros e indícios que permitam desvelar nexos mais flutuantes e condizentes com a natureza da imagem. Pois, como bem nos lembra Gottfried Boehm (2015, p. 29), é preciso compreender "o estranho estatuto flutuante da imagem, que marca seu lugar na ordem do real".

\section{A árVore da vida, O Cântico, as metáforas naturais e o romance Avalovara}

A cena que constitui o núcleo narrativo do Cântico é comum à tradição literária. Trata-se de uma espera amorosa; os amantes lamentam a ausência um do outro, enquanto exaltam a beleza, o desejo e os seus corpos:

Vem, amado, saiamos para o campo, pernoitemos nas aldeias: (13) de manhã iremos logo para as vinhas, a ver se a videira floresceu, se as flores estão-se abrindo, se floresceram as romãzeiras: ali te darei os meus amores. (14) As mandrágoras espalharam seu perfume: às nossas portas, todos os melhores frutos, novos e velhos, guardei para ti, ó meu amado (Cântico dos Cânticos $1: 12-14)$.

Procuro alguns simples apoios para sugerir minha hipótese warburguiana. Matéria não de especialista, mas de leitor que crê no gesto crítico como um trabalho de invenção também. Proponho pensar a pequena narrativa que entretece o Cântico como a nostalgia não apenas de um amor que é promessa no âmbito da diegese do poema, mas de um estado místico de graça vivido através do amor, através da experiência sexual, parte de sua estrutura simbólica profunda. $\mathrm{O}$ Cântico já seria o deslocamento dos elementos que compõem uma cena original 
incrustada na linguagem literária e que se revela em certos momentos em que ela tenta exprimir a experiência amorosa; cena sempre outra, e, ao mesmo tempo, a mesma. Essa hipotética cena original, esse tema (e aqui o utilizo no sentido propriamente musical), encontra na cosmogonia bíblica um lugar de destaque: a figuração da árvore da vida ${ }^{4}$. Tenho que insistir no fato de que não pretendo compreender a imagem da rica iconografia da árvore da vida com as ferramentas exegéticas da teologia ou da História da Arte. Interesso-me pela sua flutuação enquanto imagem, seu estatuto movente e frágil na ordem da arte e do real seus valores simbólicos. É importante que se diga que ela não constitui uma figura restrita à cultura judaico-cristã. Deve estar relacionada, muito provavelmente, com o período em que as primeiras comunidades humanas começaram a se fixar e desenvolver a agricultura, deixando a fase de coletores e caçadores. Em resumo, esse motivo é uma das imagens simbólicas mais remotas da cultura humana e está universalmente difundido.

Tomo dois pontos de partida para estabelecer relações entre o texto salomônico e a iconografia sagrada. O primeiro diz respeito ao simbolismo da árvore situada no centro da figura, centralidade essa já vislumbrada no próprio texto bíblico: “(3) Mas do fruto da árvore que está no meio do jardim, Deus disse: Dele não comereis, nele não tocareis, sob pena de morte" (Gênesis 3:3). Esse centro do mundo - esse axis mund $\imath^{5}$ - geralmente é ladeado por duas figuras humanas: um homem e uma mulher. Por vezes há animais na cena, de um lado e de outro, ou as figuras humanas podem ser substituídas por animais. Há inúmeras variações. Alguns aspectos figurativos exigem uma atenção mais cuidadosa. Ressaltam-se um princípio de simetria que se estabelece a partir do centro ocupado pela árvore e o significado que essa centralidade parece sugerir enquanto uma realidade transcendente privilegiada, porque realiza a grande síntese. Essa simetria tem por princípio a ideia de duplicidade, o homem duplo da mulher, a mulher duplo do homem. A árvore no centro é a síntese e equivale simbolicamente ao Andrógino original ${ }^{6}$. É, em seu prolífico simbolismo, um elo de coligação - não apenas entre o masculino e o feminino (quando assume o estatuto do andrógino), mas também entre os vários níveis da existência. As raízes mergulham no submundo, o tronco representa a terra e a copa, o céu transcendente.

Lembremos que há uma cogitação frequente da duplicidade que existe entre os nomes dos dois atores que compõem as personagens do Cântico: Salomão e Sulamita. Esse seria um primeiro ponto de partida para visualizar a simetria característica desse simbolismo amoroso transcendente. Inclusive, os versículos estão mais ou menos divididos igualitariamente entre as vozes poéticas masculina e feminina: um pouco mais de 50 do lado feminino e quase 50 da parte masculina. Os restantes pertencem ao coro. Em termos de sentimentalidade

4 Para ver as imagens relacionadas à iconografia da árvore da vida, uma breve incursão pela internet demonstra a extensão do tema: não apenas de origem judaico-cristã e não apenas religiosa. Mesmo a arte moderna está atravessada por essa imagem (Munch, Klint, Magritte, Portinari... a lista é inumerável). É matéria de estudo e artigo futuro o caráter central que esse motivo ocupa na tradição figurativa do Ocidente, não apenas no âmbito da arte erudita ou popular, mas no da cultura em geral.

5 O grito do neófito Kwakiutl: "Estou no Centro do Mundo!", revela-nos, de imediato, uma das mais profundas significações do espaço sagrado. Lá onde, por meio de uma hierofania, se efetuou a rotura dos níveis, operou-se ao mesmo tempo uma "abertura" em cima (o mundo divino) ou embaixo (as regiões inferiores, o mundo dos mortos). Os três níveis cósmicos - Terra, Céu, regiões inferiores - tornaram-se comunicantes. Como acabamos de ver, a comunicação às vezes é expressa por meio da imagem de uma coluna universal, axis mundi, que liga e sustenta o Céu e a Terra, e cuja base se encontra cravada no mundo de baixo (que se chama "Inferno"). Essa coluna cósmica só pode situar-se no próprio centro do universo, pois a totalidade do mundo habitável espalha-se à volta dela (ELIADE, 1992, p. 24).

6 Ver Chevallier e Gheerbrant (1988). 
amorosa, vê-se a mesma coisa: a despeito do caráter submisso da mulher, seja ela no contexto hebreu, seja ela uma noiva egípcia, filha de faraó, como defende boa parte da tradição exegética, os dois personagens compartilham da mesma e impactante liberalidade amorosa, compartilham de um similar ardor pelo corpo do outro.

Para além disso, as imagens (agora no sentido poético) são de procedência vegetal e abundantes. A natureza enquanto estado de continuidade de uma experiência radical como a sexual-amorosa é principalmente representada pelo elemento vegetal. Ele é o substrato para a construção poética desse corpo desejado e extático: "Meus irmãos irritaram-se comigo e me puseram de guardiã das vinhas, mas a minha própria vinha não guardei" (Cântico dos Cânticos 1:6); "Enquanto o rei estava no seu divã, meu nardo exalou o seu perfume" (1:12); "Meu amado é para mim como um feixe de mirra que pousa entre meus seios" (1:13); "Meu amado é para mim como um cacho de alfena das vinhas de Engadi" (1:14). Todos esses versículos foram extraídos do primeiro capítulo do Cântico. Essas metáforas vegetais são abundantes em todo o texto. Elas restituem justamente a experiência primordial da sexualidade mística e do amor transcendente. A possivel miragem da fusão que o amor proporciona em sua dimensão extática fazendo de ambos uma só carne - parece pulsar nessa linguagem figurada vegetativa e rizomática, que se esgalha, entronca e poliniza.

Passo ao último lance de minha atrevida leitura: pensar a sobrevivência dessa imagem da árvore da vida no Cântico, e como essa sobrevivência alcança um importante texto da literatura moderna brasileira.

O romance Avalovara, de Osman Lins, publicado em 1973, narra o trajeto de duas personagens que vivem a relação amorosa como uma forma de iluminação. Essa trajetória espiritual só é possível por meio da experiência corporal do amor. A carnalidade converte-se de algo impuro, sujo e reprovável em um caminho para o divino. Abel, escritor atormentado pela paixão de criar num mundo sombrio e totalitário, percorre cidades e países em busca do amor que se apresenta a ele através de três mulheres. A terceira e última constitui uma personagem sem nome, que é representada no romance por um símbolo. Ela traz dentro de si as outras duas. Há uma simetria entre essa personagem e seu amante escritor. Da mesma forma que Abel, ela vive intensamente o amor e o sexo antes de encontrá-lo.

A despeito de um diálogo ostensivo com a cultura indiana, inclusive no que diz respeito ao sexo como experiência sagrada, os ecos do Cântico se fazem presentes em muitas das passagens do romance, seja de forma mais pontual, fazendo ecoar metáforas recorrentes, como quando o vinho se transforma em metáfora do prazer que o corpo amoroso oferece - "Sua boca, tépido fruto sugador, sabe nesta escuridão a vinho e pão fresco" (LINS, 1995, p. 321), seja de forma mais alusiva e oblíqua, quando os amantes se dedicam a descrever com minúcia e ardor os prazeres do corpo um do outro: "Ó, meu amor (ouvir-me-á, se, por exemplo, são as minhas têmporas que falam?), morde-me os dentes, as unhas, as pupilas, morde-me o ombro, as coxas, prende em cada lugar seu nome verdadeiro" (LINS, 1995, p. 118) - a mulher símbolo para Abel. E ele para ela: "Amada, teu sexo me chama e articula, com doce veemência, todas as letras do meu nome. És linda. Amo os teus cabelos, teu semblante [...]. Mais do que tudo, porém, teus pés delicados: eles trouxeram-te a mim” (LINS, 1995, p. 77). Como se vê, esse tipo de enunciação lírica se espalha pelo romance, obra fronteiriça 
entre a ficção e a poesia. Naquilo que ele apresenta de mais marcadamente erótico, sente-se o princípio dessa linguagem arcaica que transforma a natureza num espelho amplificador do corpo e de suas propriedades sensoriais. Justamente nesses trechos também proliferam as imagens de procedência vegetal. Como se pode verificar num trecho mais longo que creio ser importante transcrever:

Sondo, com as pontas dos dedos, dentro da carne, o seu começo ou seu fim e não o encontro, ele continua para dentro, para dentro do ventre, por mais que eu cave com os dedos não o perco, ele continua (onde começa? onde?), impressão de que prossegue pelo corpo adentro, enreda-se em caudas, dá voltas, uma planta, arbusto rijo e vibrátil incrustado no corpo deste homem, com flores nas raizes, flores e frutos, flores de um verde carregado, frutos de um rubro semelhante aos figos. [...] O mel do teu deleite umedece-me a palma e cheira a rosas. Teu sexo me chama. Chama-me do fundo do teu ventre, é um apelo claro tão imperioso como o que nos vem, às vezes, em sonhos. Teu sexo me chama e proclama seus dons: "Sou feito de bocas, de lodo na sombra, de mãos, de flores, de peixes ávidos, de tardes estivais, de lagartas-de-fogo. Verás como hei de com dez bocas sugar a tua virilidade, verás como deslizas entre ladrilhos úmidos, limosos, verás como hei de com inúmeros e ajuizados dedos esmagar teu pênis (como quem esmaga uvas, mas teu pênis será um racimo esmagado e sempre renovado) [...], verás como hei de fazer-me em pétalas e que brandura haverá em torno desse invasor, verás como nada há de magoá-lo, como o cingirei com flores amarelas e vermelhas, como choverão, sobre o hóspede, botões de ouro, azaléas, brincos de princesa e digitalis [...] (LINS, 1995, p. 75-76).

Os ecos do Cântico ressoam nessas linhas/versos de exultação amorosa. E para além deles, a linguagem pulsante, recorrente, que o motivo icônico da árvore da vida parece sugerir. A experiência sexual se reveste de um caráter ascético, uma meditação carnal que possibilita aos amantes alcançarem também as delícias espirituais, um estado ideal e transcendente de fusão. Essa fusão se exprime de maneira muito característica na figura do andrógino, que igualmente passeia pelas páginas do romance Avalovara. Abel nos narra que, enquanto ele e a mulher-símbolo se amam sobre uma tapeçaria edênica, ele sente crescerem em seu tronco seios de mulher, e as várias partes dos corpos deles passam a se misturar e eles se transformam num nós "bicéfalo" (LINS, 1995, p. 340). Nesse caso, o bicéfalo é um estágio intermediário, um preâmbulo para a fusão amorosa final e plena.

É com a árvore, entretanto, que parece haver a aparição mais visivel dessa constelação de elementos arcaicos. Ela, como já afirmei, é o princípio natural, que, demonstrando também a mudança de um paradigma cultural primitivo, parece irradiar pela linguagem poética responsável por dar conta da mística que atravessa a experiência amorosa e sexual. Também se faz igualmente presente na narrativa do Avalovara:

Somos, junto à grande árvore, e nos seus ramos desliza alguma asa, os únicos seres humanos. Cintila sobre nós um céu armado para outras noites e encontros, o céu para nós oculto esplende aos nossos pés, pisamos à meia-noite os astros que ora nos cobrem e contra os quais se projeta, nódoa, a fronde negra e raiada de brilhos da árvore única (LINS, 1995, p. 308). 
Assim, a sobrevivência de certos elementos pode ser rastreada a partir de outra lógica. O acúmulo de variações permite uma espessura simbólica menos regida pela ideia de que o que vem antes explica o texto posterior. Nesse caso, o diálogo e a tensão do Avalovara com o Cântico ajudam a compreender a antiquíssima proveniência desses elementos que se iluminam reciprocamente. $\mathrm{O}$ inventivo romance do pernambucano Osman Lins ajuda a ler na dimensão simbólica do texto bíblico, e de maneira assumidamente anacrônica, a sobrevivência de uma cena fundamental, espalhada pelos textos culturais e reativada cada vez que desponta a experiência sexual e amorosa como via de acesso ao sagrado.

\section{CONSIDERAÇÕES FINAIS}

Preciso arrematar esse conjunto de notas e sugestões ressaltando o aspecto menos convencional do método de leitura, claramente inspirado nas ideias de Aby Warburg. Desse ponto de vista, interessam menos os comércios de influências, o jogo tradicional de pesquisa das fontes e mais o caráter constelacional das relações que são concebidas inseparáveis do observador/autor dessas notas. Em resumo, a sobrevivência não pressupõe uma sintaxe linear (árvore da vida $\rightarrow$ Cântico de Salomão $\rightarrow$ Avalovara), mas uma disposição constelar, capaz de reconstituir a imagem icônica fundamental. Essa imagem pertence ao campo do imaginário, nele sobrevive, pulsa, e ajuda a dar forma às mais variadas tentativas de expressão das paixões humanas.

\section{THE SONG OF SOLOMON AND EROTICISM: NOTES ON IMAGE AND SURVIVAL}

Abstract: The incidence of the union between the sacred and the profane, between desire and sacredness, is a striking feature of literature that contains erotism. The purpose of this article is to present some considerations about the presence of the Song of Solomon and its language in modern literature. The German theorist Aby Warburg's concept of survival allows us to perceive the recurrence of a type of metaphorical language that takes place through an ancestral pathos formula, when nature integrates the loving and mystical body with the human.

Keywords: Song of Solomon. Tree of life. Survival. Aby Warburg. Avalovara.

\section{REFERÊNCIAS}

AGAmBen, G. Ninfas. São Paulo: Hedra, 2012.

BATAILlE, G. O erotismo. São Paulo: Autêntica, 2017.

BOEHM, G. Aquilo que se mostra. Sobre a diferença icônica. In: ALLOA, E. Pensar a imagem. São Paulo: Autêntica, 2015.

CHEVAlliER, J.; GHEERBRANT, A. Dicionário de símbolos. Rio de Janeiro: José Olympio, 1988.

DIDI-HUBERMAN, G. A imagem sobrevivente. Rio de Janeiro: Contraponto, 2013. ELIADE, M. O sagrado e o profano. São Paulo: Martins Fontes, 1992.

LINS, O. Avalovara. São Paulo: Companhia das Letras, 1995. 
PAZ, O. Claude Lévi-Strauss e o festim de Esopo. São Paulo: Perspectiva, 1977. PAZ, O. A dupla chama: amor e erotismo. São Paulo: Siciliano, 2001.

WARBURG, A. Histórias de fantasmas para gente grande: escritos, esboços e conferências. São Paulo: Companhia das Letras, 2015. 